\title{
DETOXIFICATION OF STAPHYLOCOCCAL $\propto$ TOXIN BY HYDROCORTISONE AND METHYLPREDNISOLONE
}

\author{
M. J. Raff, Patricia Barnwell and the late A. S. Werner \\ Department of Medicine, Section of Infectious Diseases and Department of Microbiology \\ and Immunology, University of Louisville School of Medicine, P.O. Box 35260, \\ Louisville, Kentucky 40201, USA
}

INTERACTIONS between bacterial exotoxins and adrenocortical hormones have been described by a number of investigators (Zwemer and Jungeblut, 1935; Greene, Ambrus and Gershenfeld, 1953; Seneca, Kupyn and Johnson, 1957; Orsi, Poggiolini and Terzani, 1962). Seneca et al. (1957) reported that incubation of prednisolone hemisuccinate with " micrococcal " toxin reduced its haemolytic titre four-fold. It has been claimed that haemolysis of rabbit erythrocytes by staphylococcal $\alpha$ toxin is not inhibited by pre-incubating the toxin with cortisone, hydrocortisone, prednisolone, or dexamethasone (Orsi et al., 1962). However, these investigators found that several androgens slightly reduced the haemolytic titre of $\alpha$ toxin. This detoxification was not related to a steroid effect on the target erythrocytes, but was apparently due to an interaction between the steroids and the toxin.

There is evidence that staphylococcal $\alpha$ toxin may play a role in virulence (Werner and Ribble, 1967; Kapral, 1974). In view of the conflicting data concerning interactions between toxin and steroids, it was felt that detoxification of $\alpha$ toxin by steroids -if it could be shown to occur-might be of clinical interest. The following investigation was undertaken in an attempt to define the effects of hydrocortisone and methylprednisolone on the biological activities of staphylococcal $\alpha$ toxin.

\section{MATERIAL AND METHODS}

Purification of $\alpha$ toxin. Staphylococcal $\alpha$ toxin was prepared by a modification of the method of Bernheimer and Schwartz (1963), with a medium containing yeast extract dialysate, acid-hydrolysed casein, glucose, thiamine, and nicotinic acid. This medium was inoculated with washed cells from an overnight culture of Staphylococcus aureus, strain Wood 46, and cultures were incubated for $18-20 \mathrm{~h}$ at $37^{\circ} \mathrm{C}$ with continuous rotary agitation. Cells were removed by centrifugation at $10000 \mathrm{~g}$ for $30 \mathrm{~min}$. at $4^{\circ} \mathrm{C}$, and protein was precipitated from the supernate by $90 \%$ saturation with ammonium sulphate. The precipitate was resuspended in $0.3 \mathrm{M}$ sodium borate buffer ( $p \mathrm{H} 8 \cdot 3$ ), and ammonium sulphate was removed by dialysis against four 3-litre changes of this buffer. Further purification was accomplished by chromatographic procedures similar to those described by Rahal (1972). The crude toxin preparation was applied to a column containing diethylaminoethyl-substituted Sephadex (Pharmacia, Uppsala, Sweden) that had been equilibrated in 0.03M sodium borate at $p \mathrm{H} \mathrm{8.3.}$ Elution was accomplished with this buffer, and fractions were screened in microtitre tests for haemolytic activity. Active fractions were pooled, lyophilised to reduce volume, and subjected to carboxymethyl Sephadex chromatography. The gel was equilibrated in $0 \cdot 1 \mathrm{M}$ sodium phosphate at $p \mathrm{H} 4.0$ and eluted with $0 \cdot 1 \mathrm{M}$ sodium phosphate at $p \mathrm{H} 7 \cdot 0$. Pooled and concentrated active fractions were applied to a Sephadex G-100 column, and toxin-enriched fractions of eluate were pooled and employed in subsequent experiments. Specific activity of toxin was expressed as haemolytic units $(\mathrm{HU})$ per milligram of protein; protein was measured by the method of Lowry et al. (1951) with bovine serum albumin as standard.

Measurement of haemolytic activity. One $\mathrm{HU}$ was defined as the quantity of toxin producing $50 \%$ haemolysis. The haemolytic titre was measured on the basis of $50 \%$ haemolysis and expressed in $\mathrm{HU}$ per $\mathrm{ml}$. The haemolytic titre was determined by incubating

Received 8 Feb. 1977; revised version accepted 20 Aug. 1977.

J. MED. MICROBIOL.-VOL. 11 (1977) 
rabbit erythrocytes with serial two-fold dilutions of toxin (in phosphate buffered saline, $p \mathrm{H} \mathrm{7.2)}$ for $1 \mathrm{~h}$ at $37^{\circ} \mathrm{C}$. Unhaemolysed cells were removed by centrifugation; transmittance of the supernate was measured with a spectrophotometer (Coleman 295) at 541 $\mathrm{nm}$, and the dilution producing $50 \%$ haemolysis was recorded.

Assessment of purity. Contamination of $\alpha$ toxin by heat-stable $\delta$ haemolysin was assessed by heating purified $\alpha$-toxin preparations at $70^{\circ} \mathrm{C}$ for $1 \mathrm{~h}$, and then titrating the heated material for haemolytic activity. Purity was further evaluated by immunodiffusion against polyvalent staphylococcal antiserum and anti- $\alpha$ haemolysin (Wellcome Laboratories, Beckenham, Kent). Wells of $10 \mathrm{~mm}$ diameter were prepared in a $1.5-\mathrm{mm}$ layer of $1 \%$ Noble's agar in $0.85 \%$ sodium chloride; dilutions of polyvalent or anti- $\alpha$ antiserum or test substance were placed in the wells $(0.1 \mathrm{ml})$, and the plates were incubated at room temperature for $48 \mathrm{~h}$.

Lethality of $\alpha$-toxin preparations. Serial two-fold dilutions of $\alpha$ toxin were administered to groups of 10 Swiss Webster mice. Each animal received $0.5 \mathrm{ml}$ of toxin preparation by the intraperitoneal route and the time to death was recorded to the nearest minute.

Dermonecrotic activity. The backs of two New Zealand rabbits were shaved, and each animal was inoculated intradermally at two sites with $0 \cdot 1-\mathrm{ml}$ volumes containing $40 \mathrm{HU}$ of $\alpha$ toxin. The area of the resulting lesions was estimated at 24,48 and $72 \mathrm{~h}$.

Inhibition by corticosteroids. The effect of corticosteroids on the haemolytic activity of $\alpha$ toxin was determined by incubating toxin with various concentrations of hydrocortisone-21sodium succinate (HC) or methylprednisolone-21-sodium succinate (MP) for $60 \mathrm{~min}$. at $37^{\circ} \mathrm{C}$. These incubation conditions permitted any interaction between toxin and steroid to proceed to completion, without producing measurable loss of $\alpha$-toxin activity in the steroid-free control. After incubation, each toxin-steroid system was assayed for haemolytic activity. To determine whether steroid pretreatment influenced susceptibility to $\alpha$ toxin, rabbit red cells were incubated with various concentrations of $\mathrm{HC}$ or MP, washed with phosphatebuffered saline to remove residual free steroid, and then added to $\alpha$-toxin dilutions. Haemolytic titres were determined as previously described.

The effect of HC and MP on the intraperitoneal lethality of $\alpha$ toxin was tested by incubating various concentrations of the steroids with a quantity of toxin known to produce death in mice within 3-4 h. Mixtures of toxin and steroid were incubated for $1 \mathrm{~h}$ at $37^{\circ} \mathrm{C}$, and $0 \cdot 5-\mathrm{ml}$ volumes were administered intraperitoneally to groups of 10 Swiss Webster mice. Time to death was recorded as described above.

The protective ability of steroids in vivo was evaluated by administering these agents separately from toxin. Five milligrams of HC or MP were given intraperitoneally, subcutaneously, or intravenously, simultaneously with, or $2 \mathrm{~h}$ or $4 \mathrm{~h}$ before, intraperitoneal challenge with doses of toxin calculated to produce $100 \%$ mortality.

The effect of steroids on dermonecrotic activity of $\alpha$ toxin was studied by inoculating rabbits intradermally with mixtures of toxin and steroid that had been incubated for $1 \mathrm{~h}$. Other animals were given HC $200 \mathrm{mg}$ or MP $200 \mathrm{mg}$ intravenously $1 \mathrm{~h}$ before intradermal challenge with toxin. Lesion size and the severity of reactions were evaluated 24,48 and $72 \mathrm{~h}$ after toxin administration.

Effects of $\mathrm{HC}$ and MP on the leucocidal activity of $\alpha$ toxin could not be studied as leucocytes were killed by the concentrations of steroid required to inactivate the toxin.

\section{RESULTS}

Purification increased the specific activity from $20.5 \mathrm{HU}$ per mg protein to approximately $10000 \mathrm{HU}$ per mg protein. The ratio of $\alpha$ - to $\delta$-toxin activity in the crude filtrate was $40: 1$, and purification increased this to $280: 1$. In double gel-diffusion tests with polyvalent antiserum, purified $\alpha$ toxin gave one well-defined precipitin line and one barely-detectable line. The major band gave a reaction of identity with the precipitin line obtained against anti- $\alpha$-haemolysin antiserum.

Pre-incubation of purified toxin with HC or MP strikingly reduced its haemolytic activity for rabbit red cells (fig. 1). The haemolytic titre of the toxin control, which had been incubated for the same time in a steroid-free solution, was $690 \mathrm{HU}$ per ml. Haemolysis was 


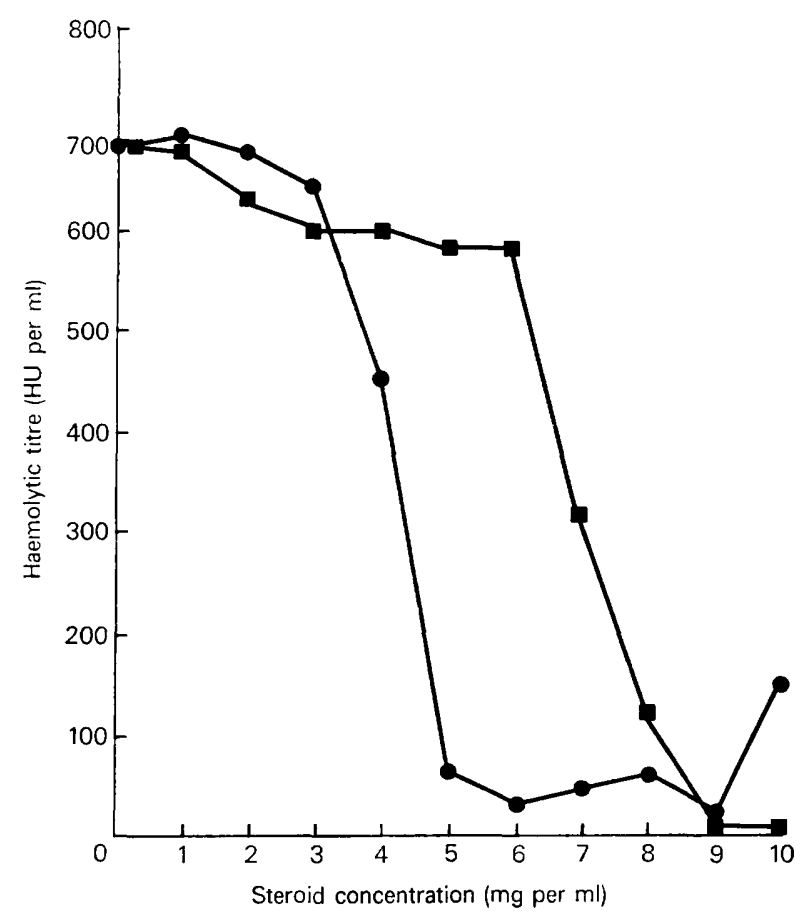

FIG. 1.-Reduction of haemolytic activity for rabbit erythrocytes by pre-incubation of staphylococcal $\alpha$ toxin with methylprednisolone $(-0)$ or hydrocortisone ( -- ). Toxin control, incubated in steroid-free phosphate-buffered saline, contained $690 \mathrm{HU}$ per ml.

inhibited by MP at a concentration of $4 \mathrm{mg}$ per $\mathrm{ml}$, whereas $7 \mathrm{mg}$ per $\mathrm{ml}$ of $\mathrm{HC}$ was required to produce a similar inhibition of haemolysis. Haemolytic activity appeared to be totally suppressed by $9 \mathrm{mg}$ of MP. However, in toxin-MP mixtures containing MP $10 \mathrm{mg}$, a haemolytic titre of $150 \mathrm{HU}$ per $\mathrm{ml}$ was found. Incubation of rabbit red cells with either MP or $\mathrm{HC}$ at $10 \mathrm{mg}$ per $\mathrm{ml}$ indicated that steroids alone can produce haemolysis at high concentrations. To assess reversibility of the toxin-steroid interaction, mixtures of toxin and steroid were dialysed against large volumes of phosphate-buffered saline. This treatment, however, failed to reverse the steroid-induced loss of haemolytic or lethal properties of $\alpha$ toxin.

When rabbit red cells were incubated with various concentrations of steroids and washed before exposure to toxin, neither HC nor MP appeared to protect red cells from haemolysis (fig. 2). At concentrations exceeding $7 \mathrm{mg}$ per ml, both HC and MP apparently altered the integrity of the erythrocyte membrane, as subsequent washing of the steroid-treated cells resulted in haemolysis. Red cells pre-incubated with either HC or MP (5 mg per ml) were haemolysed by lower concentrations of toxin than were control erythrocytes.

Effects of steroids on the lethality of $\alpha$ toxin for mice are presented in fig. 3. Toxin was pre-incubated with various concentrations of MP or HC and administered intraperitoneally to mice. Control toxin preparations (incubated with phosphate-buffered saline) contained $110 \mathrm{HU}$ per $\mathrm{ml}$ and produced death in an average of $107.5 \mathrm{~min}$. Incubation of toxin with low concentrations of steroids (MP 1-4 mg per ml, or HC 1-5 mg per ml) produced no significant changes in time to death. MP $5 \mathrm{mg}$ per $\mathrm{ml}$ and $\mathrm{HC} 6 \mathrm{mg}$ per ml produced significant prolongation of survival and, at higher concentrations, all animals survived (fig. 3 ). When mice were pretreated with $5 \mathrm{mg}$ of HC or MP and then given lethal doses of $\alpha$ toxin, there was no significant effect on time to death. 


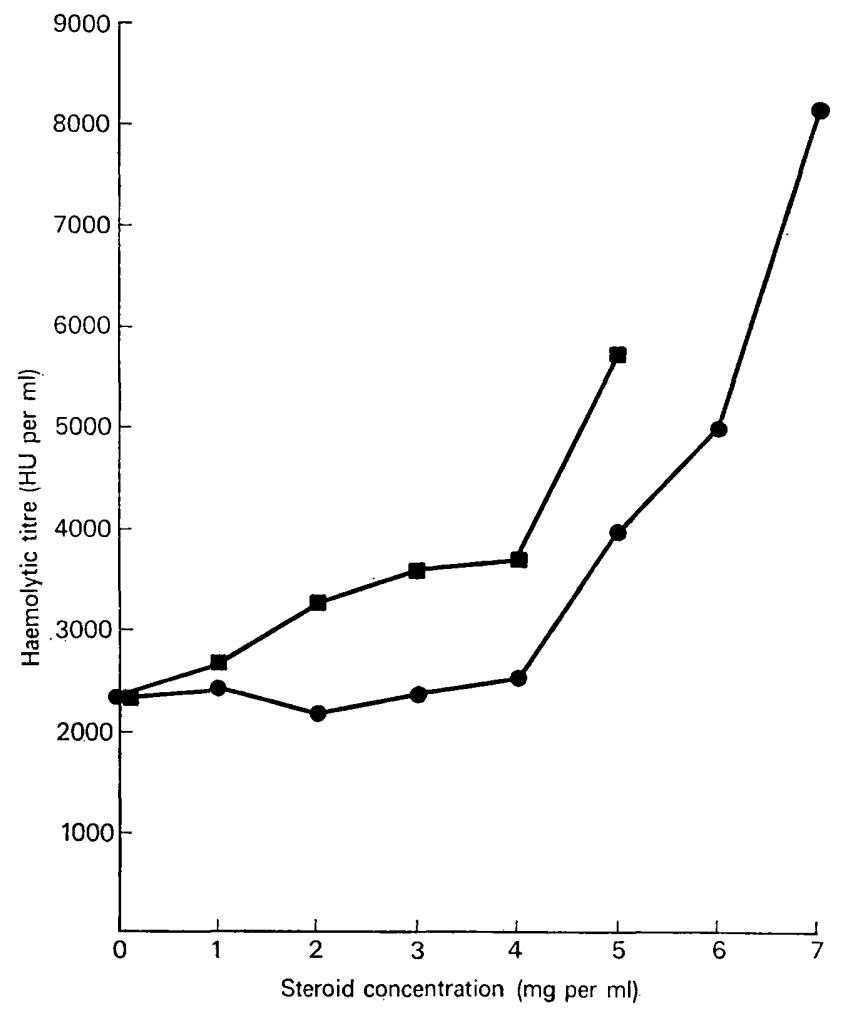

FIG. 2.-Effect of pre-incubation of rabbit erythrocytes with methylprednisolone $(\mathbf{0}-\mathbf{0})$ or hydrocortisone ( $\mathbf{\square}-\mathbf{\square})$. Red cells were treated with steroid solutions for $1 \mathrm{~h}$ and after washing were added to serial two-fold dilutions of $\alpha$ toxin.

FIG. 3. - Survival times of mice injected intraperitoneally with staphylococcal $\alpha$ toxin that had been incubated for $1 \mathrm{~h}$ with methylprednisolone (-) or hydrocortisone (ם- $\mathbf{\square})$. At concentrations exceeding MP $5 \mathrm{mg}$ per $\mathrm{ml}$ and $6 \mathrm{mg}$ per $\mathrm{ml} \mathrm{HC}$, no deaths occurred.

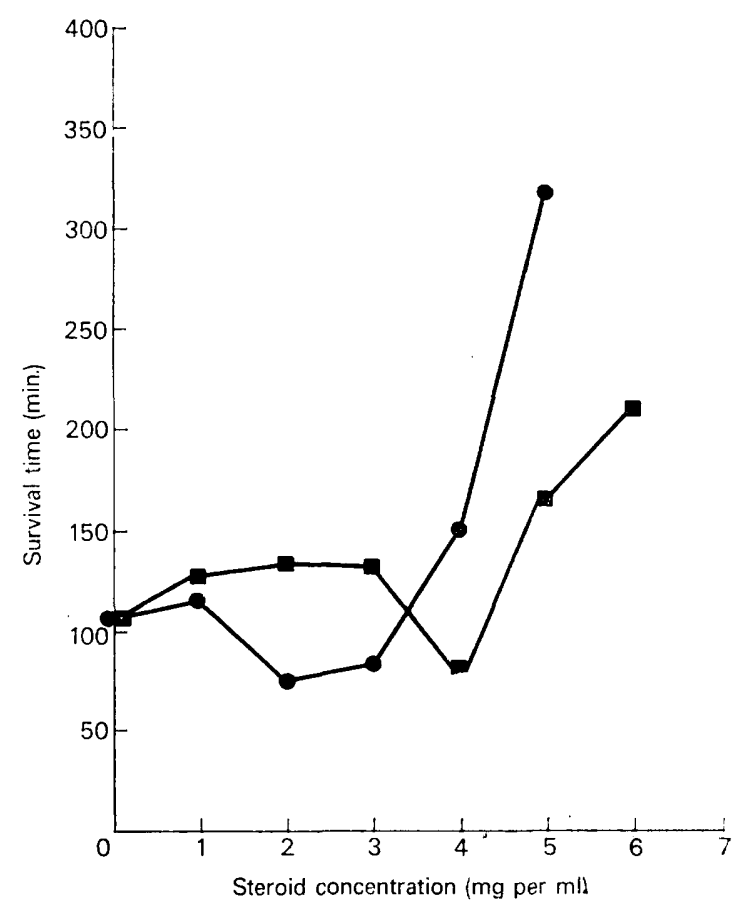


TABLE

Intradermal inoculation of rabbits with mixtures of $\alpha$ toxin and steroid

\begin{tabular}{c|cc}
\hline Steroid & $\begin{array}{c}\text { Concentration of } \\
\text { steroid (mg per ml) }\end{array}$ & $\begin{array}{c}\text { Mean lesion size } \\
\left(\mathrm{cm}^{2}\right)\end{array}$ \\
\cline { 2 - 3 } HC & 20.0 & 0 \\
HC & 10.0 & 0 \\
HC & 5.0 & 10.5 \\
HC & 2.5 & 10.5 \\
MP & 20.0 & 0 \\
MP & 10.0 & 0 \\
MP & 5.0 & 6.5 \\
MP & 2.5 & 6.5 \\
Control & 0 & 10.8 \\
\hline
\end{tabular}

$\mathrm{HC}=$ Hydrocortisone; MP = methylprednisolone

Intradermal administration of $0 \cdot 1-\mathrm{ml}$ volumes of $\alpha$ toxin $(40 \mathrm{HU})$ to rabbits produced dermonecrotic lesions measuring approximately $10 \mathrm{~cm}^{2}$. Pre-incubation of toxin (400 $\mathrm{HU}$ per $\mathrm{ml}$ ) with steroids at concentrations less than $20 \mathrm{mg}$ per $\mathrm{ml}$ resulted in a dose-related reduction of lesion size and severity, and $\mathrm{HC}$ or MP at $20 \mathrm{mg}$ per $\mathrm{ml}$ inhibited the dermonecrotic effect completely (table). No changes were observed following intradermal administration of steroids alone. Intravenous administration of $200 \mathrm{mg}$ of $\mathrm{HC}$ or MP to rabbits before intradermal challenge with toxin had no significant effect on the size or severity of dermonecrotic lesions.

\section{Discussion}

An early study (Seneca et al., 1957) indicating that bacterial exotoxins might be detoxified by steroids prompted this investigation of the effects of corticosteroids on the biological activities of staphylococcal $\alpha$ toxin.

The capability of $\alpha$ toxin to haemolyse rabbit red cells in vitro can be abolished in a doserelated fashion by incubating toxin with steroid before adding red cells. Staphylococcal $\alpha$ toxin binds to susceptible red cells and is detectable on the cell membrane by immunofiuorescence (Klainer et al., 1964). Binding of $\alpha$ toxin to the red cell membrane occurs rapidly and is independent of the subsequent membrane-damaging events that culminate in haemoglobin release (Cassidy and Harshman, 1976). Steroids are known to protect erythrocytes against mechanical stress (Fischer, 1961-62; Agarwal and Garby, 1964), and alteration of the erythrocyte membrane by steroids may also inhibit the binding of complement, thereby inhibiting immune lysis (Jennings and Taylor, 1964). Thus steroids might be expected to stabilise the red cell membrane and thereby prevent binding of toxin.

This study indicates that detoxification of staphylococcal $\alpha$ toxin by steroids occurs only as a result of a direct molecular interaction between $\alpha$ toxin and steroid. This interaction appears to produce a relatively stable toxin-steroid complex, as dialysis against large volumes of steroid-free phosphate-buffered saline did not restore haemolytic or lethal properties of the toxin.

Exposure of rabbit erythrocytes to steroids does not appear to increase the resistance of these cells to $\alpha$-toxin-induced haemolysis, despite the fact that steroids are known to stabilise the red cell membrane (Fischer, 1961-62; Agarwal and Garby, 1964; Jennings and Taylor, 1964). In fact, pre-incubation of rabbit red cells with $\mathrm{HC}$ or MP at concentrations exceeding $4 \mathrm{mg}$ per ml actually enhances their susceptibility to haemolysis by toxin. Further evidence for the direct detoxifying effect of steroids on the toxin molecule is provided by the loss of lethal effect in mice inoculated intraperitoneally, and of dermonecrotic activity in rabbits, resulting from exposure of the toxin to HC or MP. Separate administration of steroid had no effect on the lethal and dermonecrotic effects of the toxin. 
Detoxification of staphylococcal $\alpha$ toxin by steroids appears to involve binding of steroids to the toxin molecule, yielding a relatively stable complex with reduction of haemolytic, lethal and dermonecrotic activity. As amounts of $\mathrm{HC}$ and MP in excess of those required to detoxify the $\alpha$ toxin produce haemolysis in the presence or absence of toxin, it would appear that once the haemolytically-active sites on the toxin molecule have been saturated by steroid, excess steroid is free to react with the erythrocyte membrane. Interaction with HC and MP may have induced polymerisation of active monomeric $\alpha$ toxin to an inactive aggregate. Cholesterol is capable of inducing polymerisation of $\alpha$ toxin (Arbuthnott, Freer, and Billcliffe, 1973), and other compounds with a steroid nucleus may share this property.

The phenomenon of detoxification of staphylococcal $\alpha$ toxin by incubation with HC or MP appears to be a purely in-vitro interaction. The failure of steroids to remove the biological effects of $\alpha$ toxin in vivo indicates that this phenomenon would be of no clinical significance.

\section{SUMMARY}

The effects of hydrocortisone (HC) and methylprednisolone (MP) on the biological activities of staphylococcol $\alpha$ toxin were studied. Incubation of either HC or MP at concentrations of 4-8 $\mathrm{mg}$ per $\mathrm{ml}$ with purified $\alpha$ toxin $(690 \mathrm{HU}$ per $\mathrm{ml})$ reduced or eliminated haemolytic activity for rabbit red cells, intraperitoneal lethality for mice, and dermonecrotic activity for rabbits. Detoxification was related to the dose of steroid, and MP was slightly more active than HC. The mechanism of detoxification apparently involves a direct molecular interaction between $\alpha$ toxin and steroid, and pretreatment of animals with HC or MP did not enhance their resistance to the subsequent effects of toxin.

The authors thank the Upjohn Company, Kalamazoo, Michigan, USA, for providing the hydrocortisone and methylprednisolone used in this study, and Wellcome Laboratories, Beckenham, Kent, for their generous gift of polyvalent staphylococcal antiserum. Dr P. V. Liu of the Department of Microbiology and Immunology, University of Louisville School of Medicine, kindly provided the culture of Staphylococcus aureus, strain Wood 46, used to prepare $\alpha$ toxin.

\section{REFERENCES}

Agarwal, K. N. AND Garby, L. 1964. Inhibition by corticosteroids of red cell lysis in vitro. Acta endocrinol., Suppl., 93, 3.

Arbuthnott, J. P., Freer, J. H. AND Billcliffe, B. 1973. Lipid-induced polymerization of staphylococcal $\alpha$-toxin. J. gen. Microbiol., 75, 309.

BERNHEIMER, A. W. AND SCHWARTZ, L. L. 1963. Isolation and composition of staphylococcal $\alpha$-toxin. J. gen. Microbiol., 30, 455.

Cassidy, P. AND Harshman, S. 1976. Studies on the binding of staphylococcal 125I-labelled $\alpha$-toxin to rabbit erythrocytes. Biochemistry, 15, 2348.

FISCHER, H. 1961-62. Considerations on the improved preservation of erythrocytes. Folia haemat., Lpz., 78, 624.

Greene, A. E., Ambrus, J. L. And Gershenfeld, L. 1935. Effect of cortisone and desoxycorticosterone on infection with tetanus spores and upon the toxicity of tetanus toxin. Antibiotics Chemother., 3, 1121.

Jennings, J. F. AND TAYLOR, G. 1964. Effect of hydrocortisone hemisuccinate on immune lysis of sheep erythrocytes. Nature, Lond., 203, 661 .

Kapral, F. A. 1974. Staphylococcus aureus: some host-parasite interactions. Ann. N.Y. Acad. Sci., 236, 267.

Klainer, A. S., Madoff, M. A., Cooper, L. Z. And Weinstein, L. 1964. Staphylococcal alpha-hemolysin: detection on the erythrocyte membrane by immunofluorescence. Science, N.Y., 145, 714.

Lowry, O. H., Rosebrough, N. J., Randall, R. J. and Farr, A. L. 1951. Protein measurement with the Folin phenol reagent. J. biol. Chem., 193, 265. 
Orsi, N., Poggiolini, D. ANd Terzani, G. 1962. A study of the action of various steroids on staphylococcal alpha hemolysin. Riv. Biol., 55, 375.

RAHAL, J. J. 1972. Comparative effects of purified staphylococcal alpha and delta toxins on mitochondrial metabolism. J. infect. Dis., 126, 96.

SENECA, H., KupYN, O. AND Johnson, A. 1957. Effect of metisteroids on Clostridium tetani, Clostridium welchii and Micrococcus pyogenes var. aureus toxins. Antibiotics Chemother., 7, 155.

Werner, A. S. AND RibBle, J. C. 1967. Staphylococcal infection in chick embryos: the role of staphylococcal toxins in death of chick embryos. J. infect. Dis., 117, 91.

ZWEMER, R. L. AND JUNGEBLUT, C. W. 1935. Effect of various corticoadrenal extracts on diphtheria toxin in vivo and in vitro. Proc. Soc. exp. Biol. Med., 32, 1583. 